\title{
Salkowski's Reagent Test as a Primary Screening Index for Functionalities of Rhizobacteria Isolated from Wild Dipterocarp Saplings Growing Naturally on Medium-Strongly Acidic Tropical Peat Soil
}

\author{
Atiqur Rahman, ${ }^{1}$ Irnayuli R. Sitepu, ${ }^{2}$ Sui-Yan TAng, ${ }^{1}$ and Yasuyuki Hashidoko ${ }^{1, \dagger}$ \\ ${ }^{1}$ Division of Applied Bioscience, Research Faculty of Agriculture, Hokkaido University, \\ Kita 9 Nishi 9, Kita-ku, Sapporo 060-8589, Japan \\ ${ }^{2}$ Forest Microbiology Laboratory, Forest and Nature Conservation Research and Development Center, \\ Forest Research and Development Agency, Jalan Gunung Batu No. 5, P.O. Box 165, Bogor 16610, Indonesia
}

Received May 12, 2010; Accepted June 28, 2010; Online Publication, November 7, 2010

[doi:10.1271/bbb.100360]

\begin{abstract}
Rhizobacteria isolated from wild dipterocarp saplings in Central Kalimantan, Indonesia, were subjected to Salkowski's reagent test, which is often used in detecting indolic substances. Among 69 isolates grown in a low-nitrogen medium supplemented with L-tryptophan (TRP), culture fluids of 29 strains were positive to the test, in which 17 bacteria turned red and other 10 pink. All the red type rhizobacteria actively converted TRP into tryptophol (TOL), while some yielded indole-3acetic acid (IAA) with TOL production. They also showed a capacity to decompose gallotannin into pyrogallol via gallic acid. On the other hand, an active IAAproducing Serratia sp. CK67, and three Fe-solubilizing Burkholderia spp. CK28, CK43, and Citrobacter sp. CK42, were all involved in pink type rhizobacteria, which were more effective, oxidative TRP-degraders than the red type rhizobacteria. Thus, Salkowski's reagent test should be a useful primary index in the screening of functional rhizobacteria in peatland ecosystem.
\end{abstract}

Key words: Salkowski's reagent test; functional rhizobacteria; tropical peat soil; dipterocarp; IAA production

Tropical swamp forest yields woody peat soil in the forest bed, and this medium-strongly acidic soil is rich in polyphenols, enough to prevent a good growth of tree seedlings. During past decade and present, peat swamp forests in Central Kalimantan had been and are still disappearing rapidly due to excessive deforestation and peat fire. Although many attempts at reforestation to rescue natural forest vegetation have been made, many trials, including transplanting of nursery plants of local trees, were not successful due to cost problem, the properties of the soil, and unprofitable land management. ${ }^{1)}$ Hence it is necessary to find a new approach to the rehabilitation of destroyed peatland. One practical trial using biological tools has been done by our group to search in the rhizosphere for functional microorganisms that assist the growth of tree seedlings and saplings. ${ }^{2,3)}$ Using naturally grown seedlings and saplings of local soil-adapted dipterocarp trees, including some local Shorea spp., Dipterocarpus spp., and Hopea spp., as sources of functional rhizospherous microbes, we have investigated the functional rhizobacteria known as PGPR (plant growth-promoting rhizobacteria) for dipterocarp seedling.

A preliminary study indicated that these growthpromoting bacteria stimulated the development of root systems. In fact, many groups have reported an association of indole-3-acetic acid (IAA) with PGPR. ${ }^{4-6)}$ It is known that appropriate concentrations of exogenous IAA stimulate the growth and development of plant root systems. ${ }^{7)}$ Hence we speculated that some active PGPRs in peatland provide IAA or IAA agonists, which activate root branching and lateral root development. Among the rhizobacteria, active isolates showed positive reactions to Salkowski's reagent test, with a pinkish or a deep red coloration. ${ }^{8)}$ Salkowski's reagent is a $35 \% \mathrm{HClO}_{4}$ solution containing $10 \mathrm{mM} \mathrm{FeCl}_{3}$, and when mixed with IAA, tris-(indole-3-acetato)iron(III) complex is formed to display pink coloration. ${ }^{9)}$ These positive reactions of test bacteria indicate their capability of metabolizing L-tryptophan (TRP) to IAA or some analogous compounds of IAA. As exogenous IAA in the rhizosphere is a key phytohormone-like chemical substance for rootmicrobe interaction, the bio-conversion process of TRP to IAA in bacteria has been investigated well following Perley and Stowe. ${ }^{10)}$ Particularly, TRP transaminase, which catalyzes an oxidative deamination on TRP to yield indole-3-pyruvic acid (IPyA), was first reported in Enterobacter cloacae, which showed a remarkable capability of IAA production. ${ }^{112)}$ Hence Salkowski's reagent test, specified for the detection of IAA and its precursory compound IPyA, is often used for primary screening of IAA-producing rhizobacteria.

Another important factor in plant growth on peatland is trace elements, particularly $\mathrm{Fe}$ and $\mathrm{Cu}{ }^{13,14)}$ The deficiency of such metal cations in tropical peat soil is due to the polyphenolic acid-rich peat soil that possesses catechol and carboxy groups to capture these metallic cations. ${ }^{15)}$ Rhizobacteria having polyphenol-degrading abilities can decompose and quench phenolic substances present in the rhizosphere of local dipterocarp seedlings, leading to activation of their growth on tropical peat soil. In addition, rhizobacteria that can produce metal cation-chelating agents probably assist in the uptake of trace elements by local tree seedlings. Thus, peat soil-

$\dagger$ To whom correspondence should be addressed. Tel: +81-11-706-3840; Fax: +81-11-706-4182; E-mail: yasu-h@abs.agr.hokudai.ac.jp 

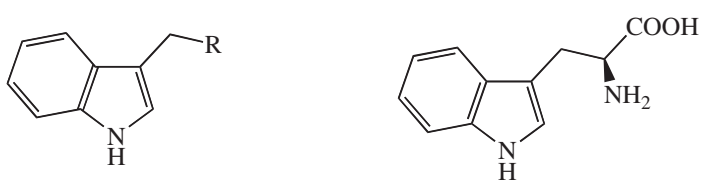

$\mathrm{R}=\mathrm{COOH}$, indole- 3 -acetic acid (IAA)

$\mathrm{R}=\mathrm{CH}_{2} \mathrm{OH}$, tryptophol (TOL)

$\mathrm{R}=\mathrm{CH}_{2} \mathrm{OCOCH}_{3}, O$-acetyltryptophol

L-tryptophan (TRP)

$\mathrm{R}=\mathrm{CH}(\mathrm{OH}) \mathrm{COOH}$, indole-3-lactic acid (ILA)

$\mathrm{R}=\mathrm{COCOOH}$, indole-3-pyruvic acid (IPyA)

Fig. 1. Chemical Structures of Indolic Compounds.

adapting local dipterocarp saplings are a good source of multifunctional rhizobacteria, and therefore, simple but effective screening for such multifunctional rhizobacteria is awaited. In this study, colorimetric responses to Salkowski's reagent test, which also shows oxidative degradation of the indolic amino acid, were investigated as a possible primary index of polyphenol-degrading and Fe-chelating rhizobacteria, along with IAA-production.

\section{Materials and Methods}

General. TLC plates (Merck Kieselgel $60 \mathrm{~F}_{254}$ Art-5715, $0.25 \mathrm{~mm}$ thick, Merck, Whitehouse Station, NJ) were used for preparative and analytical TLC. L-Tryptophan (TRP), indole-3-acetic acid (IAA), indole-3-lactic acid (ILA), indole-3-ethanol (TOL), and indole-3carboxylic acid, purchased from Wako Pure Chemical Industries (Osaka, Japan), were used as authentic compounds. $\mathrm{FeCl}_{3}$ and $\mathrm{HClO}_{4}$ to prepare Salkowski's reagent were also from Wako. ${ }^{1} \mathrm{H}$ and ${ }^{13} \mathrm{C}$ NMR analyses were recorded on a Bruker AMX-500 (Bruker, Rheinstetten, Germany) spectrometer working at 500 and $125 \mathrm{MHz}$ respectively. To measure NMR spectra, acetone- $d_{6}, \mathrm{CDCl}_{3}, \mathrm{CD}_{3} \mathrm{OD}$, and DMSO- $d_{6}$ (Sigma-Aldrich, St. Louis, MO and Wako) were used. Mass spectra were recorded on a JEOL JMS-SX102A (JEOL, Tokyo) mass spectrometer for FAB-MS and FD-MS.

Culture medium and growth conditions. The media for trapping microbes and separation of single colony were described in our previous paper. ${ }^{1)}$ The basal medium for TRP metabolism was Winogradsky's mineral solution containing $1.5 \%$ sucrose and $0.005 \%$ yeast extract to which TRP (100 $\left.\mathrm{mg}^{-1}\right)$ was added. It was adjusted to $\mathrm{pH}$ 6.0-6.2. As the inoculant, three loops of test bacterium precultured on a modified Winogradsky's agar (MWA) plate ${ }^{16)}$ for $3 \mathrm{~d}$ at $20^{\circ} \mathrm{C}$ were suspended in $2 \mathrm{ml}$ of sterile water $\left(\mathrm{OD}_{660} 0.6\right)$. For the preliminary coloration assay, $10 \mathrm{ml}$-medium was poured into a 50-ml Erlenmeyer flask, while $200 \mathrm{ml}$-medium was used in a 300-ml Erlenmeyer flask for extraction and characterization of IAA-metabolites. To the medium in a 300-ml Erlenmeyer flask, $100 \mu \mathrm{l}$ of bacterial cell suspension was inoculated, and this was standing-cultured at $28^{\circ} \mathrm{C}$ in the dark for $7 \mathrm{~d}$. For aerobic culture, $200 \mathrm{ml}$ of TRP-containing medium was shaking-cultured in a 500-ml shaking flask at $100 \mathrm{rpm}$ (Bio-Shaker BR-300LF, Taitec, Nagoya, Japan) at $28^{\circ} \mathrm{C}$ in the dark for $7 \mathrm{~d}$. For active aromatic compound-degraders, a shortened culturing period (2d) was also tested.

Bacterial isolates. Bacterial isolates were obtained from the rhizosphere of dipterocarp seedlings and saplings collected in Central Kalimantan, Indonesia. ${ }^{1)}$ The roots were then inoculated into nitrogendeficient soft gel medium of Winogradsky's mineral solution base and pre-cultured at $25^{\circ} \mathrm{C}$ in the dark for $3 \mathrm{~d}$. The trapping-cultured medium was spread over an MWA plate, and single colonies were purified as described in a previous paper. ${ }^{17)}$ Isolates grown on MWA were stored at $-80{ }^{\circ} \mathrm{C}$ as $10 \%$ glycerol cultures.

Sequence determination of the bacterial 16S rRNA gene. In some cases, a trace amount of bacterial colony was used directly as a template for PCR for the 16S rRNA gene. When this was unsuccessful, rhizobacterium grown overnight in nutrient broth medium was collected by centrifugation, and the resulting bacterial cell pellet was subjected to extraction of chromosomal DNA by the use of an Isoplant II DNA extraction kit (Nippon Gene, Toyama, Japan). Amplification of the $16 \mathrm{~S}$ rRNA gene region, sequencing of the PCR product by a direct PCR method, and searching in a database program were as described previously. ${ }^{17)}$

Salkowski's reagent test for colorimetric IAA detection. Some selected bacterial isolates were subjected to qualitative screening for IAA-producing bacteria using Salkowski's reagent $\left(2 \%\right.$ of $0.5 \mathrm{M} \mathrm{FeCl}_{3}$ in $35 \% \mathrm{HClO}_{4}$ solution) for colorimetric IAA detection in liquid culture. ${ }^{8)}$ A bacterial culture incubated in $200 \mathrm{ml}$ Winogradsky's medium supplemented with $100 \mathrm{mgl}^{-1}$ TRP for $7 \mathrm{~d}$ without any shaking was centrifuged at $10,000 \mathrm{rpm}$ for $10 \mathrm{~min}$ at $4{ }^{\circ} \mathrm{C}$, and $1 \mathrm{ml}$ of the supernatant was mixed with $2 \mathrm{ml}$ of Salkowski's reagent in a test tube. This was kept at room temperature in the dark for $30 \mathrm{~min}$. IAA production in the cultured medium was evident by a characteristic indication of reddish to pinkish color in the solution, while TRP showed a pale yellow or colorless response. According to the color intensity of the test solutions, coloring responses were grouped into two: pink type (pale pink to deep pink) and red type (dark red to red). One $\mathrm{ml}$ of an aqueous solution of $0.25 \mathrm{mM}$ IAA, $0.25 \mathrm{mM}$ TOL, or $0.25 \mathrm{~mm}$ IAA plus $0.25 \mathrm{~mm}$ TOL in water mixed with $2 \mathrm{ml}$ Salkowski's reagent was measured directly for UV spectrum (U3310 Spectrophotometer, Hitachi, Tokyo) in a range from 220 to $650 \mathrm{~nm}$ (Supplemental Fig. S1, see Biosci. Biochem. Biotechnol. Web site).

Extraction, detection, and quantification of indole derivatives on $T L C$ and HPLC. Salkowski's reagent was also used as a chromogenic spraying reagent to detect IAA and other indole derivatives derived from TRP on TLC plates. ${ }^{18)}$ IAA, TOL, ILA, and TRP were used as authentic indole derivatives, while IPyA was confirmed by ${ }^{1} \mathrm{H}$ NMR spectra of the EtOAc extract from a 2-d shaking culture of CK67. After $7 \mathrm{~d}$ of incubation in standing culture, cultured media were centrifuged at $10,000 \mathrm{rpm}$ for $10 \mathrm{~min}$, and the resulting supernatant was acidified with $2 \mathrm{M} \mathrm{HCl}$ to $\mathrm{pH} 2.5 .^{2}$ The supernatants were extracted with equal volumes of EtOAc three times. After it was concentrated and redissolved in $2.0 \mathrm{ml}$ EtOAc, the volumetric solution was used in semiquantitative analysis of the TRP metabolites. As a preliminary, $5 \mu 1$ was exactly charged on TLC using a volumetric glass capillary. Indole compounds were detected on silica gel TLC plates developed in $\mathrm{CHCl}_{3}$-EtOAc-HCOOH at 11:5:4. Chemical spots observed under UV $254 \mathrm{~nm}$ were sprayed with Salkowski's reagent and then slightly heated. Each indole compound showed characteristic, stable coloration: reddish pink for IAA, reddish yellow for TRP, and vivid yellow for TOL and ILA.

HPLC was done to quantify the major TRP metabolites, IAA, TOL, ILA, and tentative IPyA, in a reverse-phase column (L-column2 ODS $5 \mu \mathrm{m}, 4.6 \mathrm{~mm}$ i.d. $\times 250 \mathrm{~mm}$, Chemicals Evaluation and Research Institute, Tokyo) using $\mathrm{MeOH}: 1 \% \mathrm{CH}_{3} \mathrm{COOH}, 25: 75^{19)}$ as an isocratic mobile phase, with a UV detector at $280 \mathrm{~nm}$. The retention times of TRP, ILA, TOL, IPyA, and IAA were $t R$ 6.3, 22.8, 29.0, 30.9, and 33.5 min respectively (Figs. 1 and 2). The absolute calibration method was used for the HPLC quantification of IAA to give a coefficient of $0.6 \times 10^{3}$ (as peak intensity per ng IAA).

Purification of indole compounds from the crude extracts was done by silica gel column chromatography, and continuously by preparative thin layer chromatography using silica gel TLC plates. All the major metabolites (IAA, TOL, ILA, and catechol), except for IPyA, were purified by column chromatography, and each structure was confirmed by ${ }^{1} \mathrm{H}$ and mass spectroscopic (FD-HR-MS or FAB-HR-MS) analysis.

TRP metabolism in different $p H$. Bacterial isolates CK23 and CK67 were tested to determine whether these bacteria are equally capable of metabolizing TRP at various $\mathrm{pH}$ levels. An MW solution supplemented with $100 \mathrm{mg}^{-1}$ TRP was adjusted to $\mathrm{pH} 4.0,5.0,6.0,7.0$, and 8.0 using $2 \mathrm{M} \mathrm{H}_{2} \mathrm{SO}_{4}$. To $100 \mathrm{ml}$ of the TRP-amended medium, a loop of bacteria was inoculated and standing-cultured for $7 \mathrm{~d}$ in the dark at $28{ }^{\circ} \mathrm{C}$. The process of extracting TRP metabolites was as described above.

Tannic acid degradation. Since both the tropical woody peat soil and the root bark of dipterocarp plant were rich in diverse polyphenols, ${ }^{20,21)}$ we also investigated the tannic acid (TA)-degrading 
Table 1. Isolation of Rhizobacteria from Dipterocarp Saplings

\begin{tabular}{|c|c|c|c|c|}
\hline Isolation source & Code & Identification & Subclass & Response \\
\hline \multicolumn{5}{|l|}{ (Pink type) } \\
\hline \multirow[t]{2}{*}{ Hopea sp. } & CK2 & Pseudomonas sp. & $\gamma$-Proteobacteria & pale pink \\
\hline & CK42 & Citrobacter sp. & $\gamma$-Proteobacteria & pink \\
\hline Shorea parvflora & CK13 & Enterobacter sp. & $\gamma$-Proteobacteria & pale pink \\
\hline \multirow[t]{4}{*}{ S. teysmanniana } & CK26 & Azospirillum sp. & $\alpha$-Proteobacteria & pink \\
\hline & CK28 & Burkholderia sp. & $\beta$-Proteobacteria & pale pink \\
\hline & CK59 & Burkholderia sp. & $\beta$-Proteobacteria & pale pink \\
\hline & CK61 & Citrobacter sp. & $\gamma$-Proteobacteria & pink \\
\hline S. balangeran & CK43 & Burkholderia sp. & $\beta$-Proteobacteria & pale pink \\
\hline \multirow[t]{2}{*}{ Dipterocarpus sp. } & CK22 & Serratia sp. & $\gamma$-Proteobacteria & pale pink \\
\hline & CK67 & Serratia sp. & $\gamma$-Proteobacteria & pale pink \\
\hline \multicolumn{5}{|l|}{ (Red type) } \\
\hline \multirow[t]{2}{*}{ Hopea sp. } & CK15 & Roseateles sp. & $\gamma$-Proteobacteria & red \\
\hline & CK40 & Klebsiella sp. & $\gamma$-Proteobacteria & deep red \\
\hline \multirow[t]{5}{*}{ Dipterocarpus sp. } & CK23 & Enterobacter sp. & $\gamma$-Proteobacteria & red \\
\hline & CK24 & Erwinia sp. & $\gamma$-Proteobacteria & deep red \\
\hline & CK34 & Stenotrophomonas sp. & $\gamma$-Proteobacteria & red \\
\hline & CK35 & Enterobacter sp. & $\gamma$-Proteobacteria & deep red \\
\hline & CK36 & Pantoea sp. & $\gamma$-Proteobacteria & deep red \\
\hline \multirow[t]{5}{*}{ Shorea balangeran } & CK4 & Klebsiella sp. & $\gamma$-Proteobacteria & deep red \\
\hline & CK5 & Serratia sp. & $\gamma$-Proteobacteria & deep red \\
\hline & CK6 & Klebsiella sp. & $\gamma$-Proteobacteria & deep red \\
\hline & CK64 & Enterobacter $\mathrm{sp}$. & $\gamma$-Proteobacteria & deep red \\
\hline & CK65 & Enterobacter sp. & $\gamma$-Proteobacteria & deep red \\
\hline \multirow[t]{2}{*}{ S. parvflora } & CK10 & Erwinia sp. & $\gamma$-Proteobacteria & deep red \\
\hline & CK12 & Erwinia sp. & $\gamma$-Proteobacteria & deep red \\
\hline \multirow[t]{2}{*}{ S. teysmanniana } & CK53 & Pantoea sp. & $\gamma$-Proteobacteria & deep red \\
\hline & CK54 & Pantoea sp. & $\gamma$-Proteobacteria & deep red \\
\hline S. stenoptera & CK69 & Enterobacter sp. & $\gamma$-Proteobacteria & deep red \\
\hline \multicolumn{5}{|l|}{ (Intermediary type) } \\
\hline \multirow[t]{2}{*}{ Shorea teysmanniana } & CK18 & Klebsiella sp. & $\gamma$-Proteobacteria & pale red \\
\hline & CK19 & Rhizobium sp. & $\alpha$-Proteobacteria & pale red \\
\hline \multicolumn{5}{|c|}{ (Colorless, two selected isolates) } \\
\hline Shorea balangeran & CK32 & Burkholderia sp. & $\beta$-Proteobacteria & colorless \\
\hline S. teysmanniana & CK63 & Pseudomonas sp. & $\gamma$-Proteobacteria & colorless \\
\hline
\end{tabular}

Salkowski's reagent test was done at 10-ml volume in a 50-ml Erlenmeyer flask.

capability of the rhizobacteria. To $100 \mathrm{ml}$ of modified Winogradsky's liquid medium supplemented with TRP, TA (averaged molecular weight, $1,700,1.7 \mathrm{~g}^{-1}$ ) was added as model polyphenolic to approximately $1 \mathrm{~mm}$ concentration, and all 29 rhizobacteria were shaking-cultured for $2 \mathrm{~d}$ as described above. The supernatant of the cultured medium was adjusted to $\mathrm{pH} 3.0$ or less with $1 \mathrm{M} \mathrm{HCl}$, and extracted twice with equal volumes of EtOAc. The culture fluid with or without $1 \mathrm{~mm}$ TA was extracted with EtOAc as described in this paper, and EtOAc solubles were analyzed by the TLC system, with spraying of Salkowski's reagent or Gibbs reagent to detect polyphenols.22) Isolation and identification of the major bio-conversion products from TA were done as described in a previous paper. ${ }^{23)}$

Detection of IAA in the culture fluid of IAA-producing Serratia $s p$. CK67 standing-cultured in liquid medium without supplemental TRP. Serratia sp. CK67, an active IAA-producing bacterium, was used in this experiment. The medium $(200 \mathrm{ml})$, supplemented with $50 \mathrm{mg}^{-1}$ yeast extract and $0.05 \% \mathrm{NH}_{4} \mathrm{NO}_{3}\left(0.5 \mathrm{~g} \mathrm{l}^{-1}\right)$, was standing-cultured for 3 weeks, and after separation of bacterial cells by centrifugation at $8,000 \times g$ for $10 \mathrm{~min}$, the culture fluid was passed through conditioned Cosmosil 75C18-OPN (120g, Nacalai Tesque, Kyoto, Japan) on a Buchner funnel, and this was then washed with a sufficient volume of Milli-Q water $(200 \mathrm{ml} \times 3)$. After removal of the void water by vacuum, the substances trapped by the Cosmosil particles were eluted with $600 \mathrm{ml} \mathrm{MeOH}$. Then the resulting eluate was concentrated and redissolved to $2 \mathrm{ml}$-volumetric solution, of which $5 \mu \mathrm{l}$ was subjected to semi-quantitative TLC and quantitative HPLC analyses.

Plate assay for bacterial siderophores using chrome azurol $S$ $(C A S)$. Screening of bacteria able to produce Fe-chelating substances was done using chrome azurol $\mathrm{C}$ (CAS)-containing agar plates, as described in the original paper. ${ }^{24)} \mathrm{A}$ basal medium, $100 \mathrm{ml}-\mathrm{MM} 9$ salt solution $\left(3 \mathrm{gl}^{-1} \mathrm{KH}_{2} \mathrm{PO}_{4}, 5 \mathrm{gl}^{-1} \mathrm{NaCl}\right.$, and $\left.10 \mathrm{gl}^{-1} \mathrm{NH}_{4} \mathrm{Cl} ; \times 10\right)$, $30.24 \mathrm{~g}$ of PIPES, and $12 \mathrm{ml}$ of $50 \% \mathrm{NaOH}$ solution mixed in $750 \mathrm{ml}$ of Milli-Q water, was solidified with $1.5 \%$ agar and autoclaved. Into the liquefied medium, a CAS-Fe(III)-containing hexadecyltrimethyl ammonium bromide solution was gently mixed and casted on Petri dishes. Since the basal MM9 medium contained sufficient amounts of phosphate and ammonium, some oligotrophic bacteria grew well on the plate. Hence each bacterial isolate was inoculated on the CAS plate by means of toothpicks. A positive response in the CAS assay gave a clear, yellowish halo-zone around the grown colony on a blue background.

\section{Results and Discussion}

In our investigation of functional rhizobacteria from collected saplings of Shorea spp., Hopea sp., and Dipterocarpus sp. growing naturally in tropical peatland in Central Kalimantan, Indonesia, many isolates showed PGPR activity for $S$. balangelan and $S$. selanica seedlings. ${ }^{3)}$ Of the 69 bacterial isolates from the rhizosphere of these dipterocarp saplings, approximately half (34 isolates) showed positive color reactions to Salkowski's reagent. According to coloration, these positive isolates were grouped into three types: a pink type (CK2, 13, 22, $26,28,42,43,59,61$, and 67), a red type (CK4, 5, 6, 10, $12,15,23,24,34,35,36,40,53,54,64,65$, and 69), and 

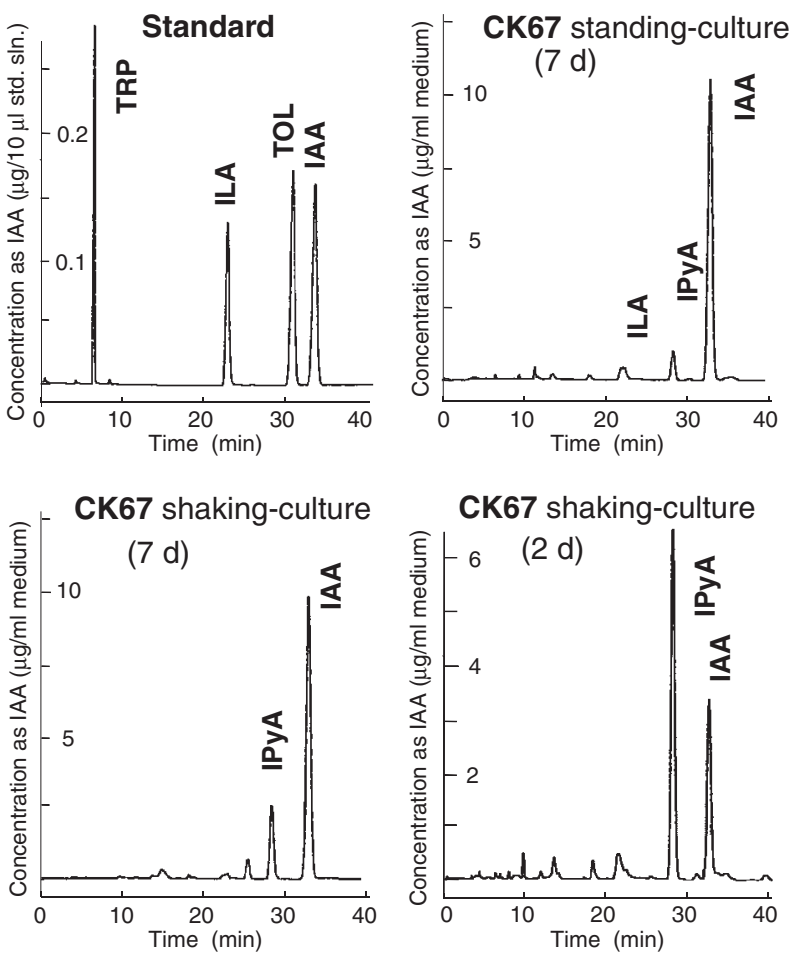

Fig. 2. HPLC Profiles of TRP Metabolites Yielded by IAA-Producing Serratia sp. CK67 under Aerobic and Anaerobic Conditions.

For the anaerobic condition, standing culture was selected, while shaking culture was set at $100 \mathrm{rpm}$ for the aerobic conditions, and liquid media of $200 \mathrm{ml}$ were cultured for $7 \mathrm{~d}$. Milli-Q water containing $0.25 \mathrm{~mm}$ TRP and $0.5 \mathrm{~mm}$ ILA, TOL, and IAA was used as standard solution, of which $10 \mu \mathrm{l}$ was subjected to HPLC. Identification of the major peaks in these HPLC profiles at $280 \mathrm{~nm}$ was done by a double injection of standard IAA to detect major substance at the same retension time. Compared to the 7-d standing culture and the 7-d-shaking culture, 2-d-shaking culture maintained IPyA. All the extracts were re-dissolved in $2.0 \mathrm{ml} \mathrm{MeOH}$, and $5 \mu \mathrm{l}$ of the volumetric solution was subjected to HPLC analysis. The scale of the vertical axis shows the concentration of IAA in the cultured medium $(\mu \mathrm{g} / \mathrm{ml})$ as a representative indolic compound.

an intermediary type (CK18 and 19), and tentative identification at the genus level by determination of $16 \mathrm{~S}$ rRNA gene sequence (Table 1) was done. Two bacteria (CK32 and 63) that responded negatively to Salkowski's reagent were also selected for comparisons to the positive ones. Generally, bacteria grown under nitrogenlimiting conditions enhance the level of deaminase for effective recycling of nitrogen from amino acids, ${ }^{25}$ ) but some bacteria use transaminase for the oxidative deamination reaction on L-tryptophan (TRP) to yield IAA via intermediary indole-3-pyruvic acid (IPyA). ${ }^{26)}$ Although TRP contains two nitrogen atoms, an $\mathrm{N}$ in the indole ring is less degradable than the other $\mathrm{N}$ in the $\alpha$-amino group. Therefore, active saprophytes possessing indole oxidase completely degrade TRP via anthranilic acid and then catechol, ${ }^{27}$ and do not produce indole-3-acetic acid (IAA).

Among the rhizobacteria positive to Salkowski's reagent, Serratia sp. CK67 was selected as the most selective and effective IAA-producer from exogenous TRP under both aerobic and anaerobic culture conditions (Table 2 and Fig. 2). Compared to aerobic culturing for $7 \mathrm{~d}, 2$-d-aerobic culturing resulted in a peak at $t R$ 28.5 min in HPLC identical to IPyA. Similarly, Serratia CK22, Citrobacter sp. CK42, and Citrobacter sp. CK61,
Table 2. Bio-Conversion of TRP by Mainly Two Groups of Rhizobacteria to Show Different Responses toward Salkowski's Reagent Test

\begin{tabular}{lllll}
\hline \hline \multirow{2}{*}{ Isolate } & \multicolumn{2}{l}{ Standing-culture } & & \multicolumn{2}{l}{ Shaking-culture } \\
& IAA $\quad$ TOL & & IAA IPyA
\end{tabular}

(Pink type)

Pseudomonas sp. CK2

Enterobacter sp. CK13

Serratia sp. CK22

Azospirillum sp. CK26

Burkholderia sp. CK28

Citrobacter sp. CK42

Burkholderia sp. CK43

Burkholderia sp. CK59

Citrobacter sp. CK61

Serratia sp. CK67

IAA

(Red type)

Klebsiella sp. CK4

Serratia sp. CK5

Klebsiella sp. CK6

Erwinia sp. CK10

Erwinia sp. CK12

Roseateles sp. CK15

Enterobacter sp. CK23

Erwinia sp. CK24

Stenotrophomonas sp. CK34

Enterobacter sp. CK35

Pantoea sp. CK36

Klebsiella sp. CK40

Pantoea sp. CK53

Pantoea sp. CK54

Enterobacter sp. CK64

Enterobacter sp. CK65

Enterobacter sp. CK69

(Intermediary type)

Klebsiella sp. CK18

Rhizobium sp. CK19

(Colorless type)

Burkholderia sp. CK32

Pseudomonas sp. CK63

++ , major spot (over $5 \mu \mathrm{g} / \mathrm{ml}$ medium); + , minor spot; \pm , trace spot; - , not detected; NT, not tested. Both in standing culture and shaking culture, incubation was done for $7 \mathrm{~d}$.

aerobic-cultured for $7 \mathrm{~d}$, gave IAA as the major metabolite from TRP (Supplemental Fig. 2; see Biosci. Biotechnol. Biochem. Web site). Including Serratia sp. CK67, they had no or low ability to degrade IAA (data not shown), and thus it is plausible that they accumulated IAA in the TRP-supplemented cultured medium. All these effective IAA-producing bacteria are members of the pink type rhizobacteria (Table 2). None of the members of this group produced tryptophol (TOL) or DL-indole-3-lactic acid (ILA) under anaerobic culture conditions.

In contrast, the red type rhizobacteria, Klebsiella spp. CK4 and CK6 and Serratia sp. CK5, effectively converted TRP into TOL with active IAA production, particularly in standing culture (CK4 and CK6 in Fig. 3). Under the same anaerobic culture conditions, Erwinia sp. CK10, CK12, and CK24, Enterobacter sp. CK23, and Pantoea spp. CK36 and CK53 yielded TOL and ILA, without production of IAA (see CK12 and CK23 selected as typical TOL-ILA producing rhizobacteria) (Fig. 3). Thus TOL production under anaerobic 

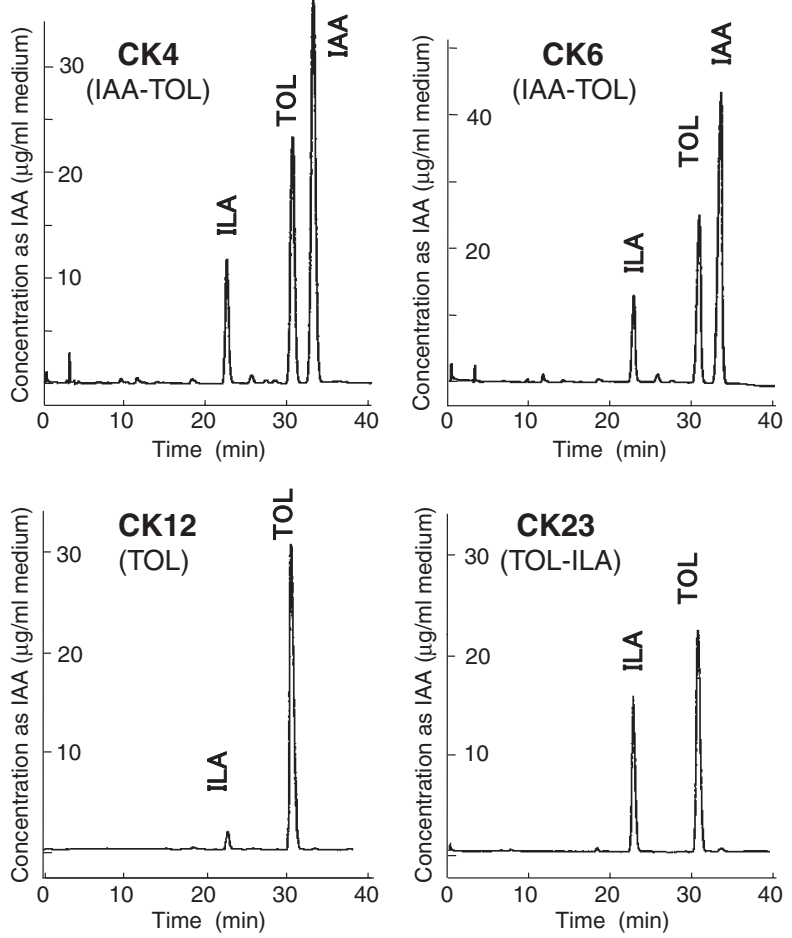

Fig. 3. HPLC Profiles of Anaerobic TRP Metabolites Yielded by TOL-ILA-Producing Rhizobacteria of the Red Type toward Salkowski's Reagent.

All the HPLC profiles were under anaerobic culture conditions for $7 \mathrm{~d}$. For standard compounds as references, the profile of the standard mixture shown in Fig. 3 should be used. All the extracts from the culture fluid of the red type rhizobacteria were re-dissolved in $2.0 \mathrm{ml} \mathrm{MeOH}$. The volumetric solution was diluted 10 times with fresh $\mathrm{MeOH}$, of which $5 \mu \mathrm{l}$ was subjected to HPLC analysis. (IAATOL) in the figure means a metabolic pattern predominantly producing both IAA and TOL, while (TOL-ILA) shows a pattern producing TOL and ILA but not IAA. (TOL) produces only TOL.

culture conditions appears to be characteristic of the red type rhizobacteria. Even in shaking culture for $7 \mathrm{~d}$, some isolates produced TOL as a major product, together with significant amounts of IAA (see CK5 and CK19 selected as typical TOL-IAA producing rhizobacteria under aerobic conditions) (Supplemental Fig. 3; see Biosci. Biotechnol. Biochem. Web site).

TOL is known to be derived from endogenous IAA by plants, and it is immediately converted to $O$-acetyl tryptophol, which is stocked in plant tissues. ${ }^{28)} \mathrm{TOL}$ is also known as an antimicrobial substance and a weak auxin agonist, ${ }^{29)}$ and it has been identified as an apoptosis-inducing factor in a human leukemic cell line. ${ }^{30)}$ Hence, it might be necessary to investigate the association of TOL with plant apoptosis.

In bio-conversion experiments at various $\mathrm{pH}$ levels ( $\mathrm{pH} 4.0,5.0,6.0,7.0$, and 8.0 before autoclaving) for five isolates selected (pink type, Azospirillum sp. CK26 and Serratia sp. CK67; red type, Klebsiella sp. CK6 and Enterobacter sp. CK23; and a colorless type, Burkholderia sp. CK32), all the rhizobacteria except for Serratia sp. CK67 showed good growth performance at all $\mathrm{pH}$ values. Klebsiella sp. CK6 uniquely produced $O$-acetyl tryptophol at $\mathrm{pH} 5.0$ as a major metabolite from TRP, although TOL was major substance produced at $\mathrm{pH} 6.0$ and 7.0 (Fig. 3). In contrast, Serratia sp. CK67, selectively producing IAA, did not grow at $\mathrm{pH} 5.0$ or lower, but grew well in a range from $\mathrm{pH} 6.0$ to 8.0. The
IAA production of CK67 was uniquely active at $\mathrm{pH} 7.0$ but inactive at $\mathrm{pH}$ 8.0. Peat soil-adapted local trees maintain their rhizosphere $\mathrm{pH}$ in the neutral region ( $\mathrm{pH}$ 6.0-7.2), although tropical peat soil itself indicates more acidic, ranging from $\mathrm{pH} 3.8-4.5 .^{31)}$ The appropriate $\mathrm{pH}$ range for the IAA production of CK67 suggests that Serratia sp. CK67 is a genuine rhizobacterium preferably inhabiting the rhizosphere of dipterocarp saplings to assist the growth of the host plants.

As polyphenols and humic acid cut down on the availability of phosphorus and trace elements, tropical peat soil that is extremely rich in these aromatic substances often inhibits plant growth. ${ }^{13,14)}$ If rhizospherous bacteria can degrade such pholyphenols and humic substances, they can be important partners for local plants inhabiting the peatland ecosystem. To determine whether these polyphenol-degrading bacteria contribute to reducing the adversity of tropical peat soil in the rhizosphere, a polyphenol-metabolizing experiment was done under a shaking-culture condition with exposure to $1 \mathrm{~mm}$ tannic acid (TA). As the culture medium, the medium used for TRP metabolizing assay was subjected to this experiment because TRP is an available nitrogen source. Among 15 red type and 2 intermediary type rhizobacteria isolated from polyphenol-rich environments, 11 isolates produced pyrogallol (PY) from TA via non-oxidative decarboxylation of precursory gallic acid (GA) (Table 3). On the other hand, the responses of the pink type rhizobacteria to TA-degradation were clearly distinguishable from those of the red ones. After $2 \mathrm{~d}$ of incubation under aerobic conditions, four pink type bacteria, Pseudomonas sp. CK2, Enterobacter sp. CK13, Azospirillum sp. CK26, and Burkholderia sp. CK43, thoroughly degraded TRP to catechol (CA) via anthranilic acid. ${ }^{27)}$ However, these four isolates gave on TLC neither PY nor other metabolites of TA. Furthermore, four other isolates yielded GA as breakdown products of TA, but none of them gave PY (Table 3). Thus, the color type of the rhizobacteria in Salkowsky's reagent test reflected their metabolic properties for TA-degradation.

To confirm the practical contribution of IAA-producing rhizobacteria to dipterocarp seedlings in the peatland ecosystem, it is also necessary to characterize stable providers of TRP. In some studies, it has been reported that significant amounts of TRP are exuded from the roots of some plant seedlings, such as oat $(21-29 \mu \mathrm{g} / \mathrm{g}$ of 3-d-grown fresh seedlings) ${ }^{32)}$ and radish (0.3-0.4 $\mu \mathrm{g} /$ seedling). ${ }^{33)}$ In contrast, low exudation of TRP has also been reported for some other plants, such as cucumber, showing only $0.002 \mu \mathrm{g}$ /seedling. ${ }^{34)}$ Thus, the capability of plant roots to exude TRP into the rhizosphere is dependent on the plant species, along with environmental conditions of the seedlings. Huang and Villanueva have analyzed the amino acid contents of the seedlings of some dipterocarp plants, but offered no particular description for TRP. ${ }^{35)}$

Another possible source of TRP is the rhizobacteria themselves. It is known that wild Corynebacterium glutamicum and Bacillus subtilis effectively produce TRP in culture, ${ }^{36)}$ but many reports have also indicated that TRP is the most costly biosynthesized amino acid among 20 constitutive amino acids as protein components. ${ }^{37)}$ When we cultured IAA-producing Serratia sp. 
Table 3. Some Functionalities of Mainly Two Groups of Rhizobacteria According to Salkowski's Reagent Test

\begin{tabular}{|c|c|c|c|c|}
\hline Isolates & GA & PY & $\mathrm{CA}$ & CAS \\
\hline \multicolumn{5}{|l|}{ (Pink type) } \\
\hline Pseudomonas sp. CK2 & - & - & ++ & \pm \\
\hline Enterobacter sp. CK13 & - & - & ++ & \pm \\
\hline Serratia sp. CK22 & ++ & \pm & - & - \\
\hline Azospirillum sp. CK26 & - & - & ++ & - \\
\hline Burkholderia sp. CK28 & - & ++ & \pm & ++ \\
\hline Citrobacter sp. CK42 & ++ & \pm & - & ++ \\
\hline Burkholderia sp. CK43 & - & \pm & ++ & ++ \\
\hline Burkholderia sp. CK59 & - & \pm & - & - \\
\hline Citrobacter sp. CK61 & ++ & \pm & - & - \\
\hline Serratia sp. CK67 & + & \pm & - & - \\
\hline \multicolumn{5}{|l|}{ (Red type) } \\
\hline Klebsiella sp. CK4 & + & ++ & - & \pm \\
\hline Serratia sp. CK5 & ++ & + & - & - \\
\hline Klebsiella sp. CK6 & + & ++ & - & - \\
\hline Erwinia sp. CK10 & + & ++ & - & \pm \\
\hline Erwinia sp. CK12 & + & ++ & - & \pm \\
\hline Roseateles sp. CK15 & + & ++ & - & \pm \\
\hline Enterobacter sp. CK23 & + & ++ & - & \pm \\
\hline Erwinia sp. CK24 & + & ++ & - & \pm \\
\hline Stenotrophomonas sp. CK34 & - & \pm & - & - \\
\hline Enterobacter sp. CK35 & \multicolumn{2}{|c|}{ NT } & - & \pm \\
\hline Pantoea sp. CK36 & \multicolumn{2}{|c|}{ NT } & - & - \\
\hline Klebsiella sp. CK40 & - & - & - & - \\
\hline Pantoea sp. CK53 & + & ++ & - & \pm \\
\hline Pantoea sp. CK54 & + & ++ & - & \pm \\
\hline Enterobacter sp. CK64 & ++ & \pm & - & - \\
\hline Enterobacter sp. CK65 & \multicolumn{2}{|c|}{ NT } & - & - \\
\hline Enterobacter sp. CK69 & \multicolumn{2}{|c|}{ NT } & - & - \\
\hline \multicolumn{5}{|l|}{ (Intermediary) } \\
\hline Klebsiella sp. CK18 & ++ & ++ & - & - \\
\hline Rhizobium sp. CK19 & ++ & ++ & - & \pm \\
\hline \multicolumn{5}{|l|}{ (Colorless) } \\
\hline Burkholderia sp. CK32 & ++ & + & - & - \\
\hline Pseudomonas sp. CK63 & ++ & - & - & \pm \\
\hline
\end{tabular}

GA, gallic acid; PY, pyrogallol; CA, catechol. Bio-conversion of TA into GA and PY, and production of CA from TRP are shown here. GA production suggests bacterial functionality to be tolerant to polyphenols and to degrade hydrolysable tannins, while PY production shows non-oxidative decarboxylation of gallic acid. CA reflects high anthrani activity to cleave ++ , major; + , minor; \pm , trace; - , not detected. CAS indicates CAS assay for bacterial siderophore. ++ , size of Fe-chelating halo-zone is over $5 \mathrm{~mm}$; + , halo-zone is visible, but its size of less than $5 \mathrm{~mm}$; \pm , weak positive to change the color only on edge of the colony; - , negative.

CK67 cultured in $\mathrm{NH}_{4} \mathrm{NO}_{3}$-amended Winogradsky's medium $\left(0.005 \%\right.$ yeast extract and $0.05 \% \mathrm{NH}_{4} \mathrm{NO}_{3}$ for nitrogen source, $0.5 \%$ sucrose and $\mathrm{pH} 6.0$, without any supplemental TRP) as standing culture for 3 weeks, this TRP-degrading bacterium produced IAA in the culture fluid as a major metabolite at $98 \mu \mathrm{g} \mathrm{l}{ }^{-1}$ of the cultured medium (Fig. 4). Since yeast extract generally contains about $0.3 \% \mathrm{w} / \mathrm{w}$ of TRP, $0.005 \%$ yeast extract-amended medium approximately provides $150 \mu \mathrm{g} 1^{-1}$ of TRP. If all the TRP in yeast extract were converted to IAA, the concentration of IAA would be $128 \mu \mathrm{gl}^{-1}$, almost at the same level as IAA produced by CK67 cultured without supplemental TRP. This implies that Serratia sp. CK67 converted almost all the TRP in the medium, even though the concentration of TRP was only a trace. This ability might lie in the rhizoplane of host plants.

Since it is known that available cations of essential metals, including $\mathrm{Fe}, \mathrm{Cu}, \mathrm{Mo}$, and $\mathrm{Zn}$, are absolutely
Standard
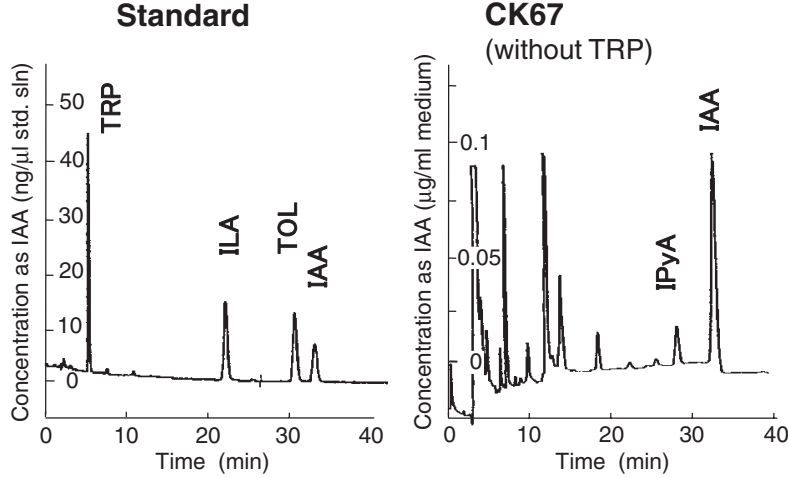

Fig. 4. HPLC Profiles of Metabolites Yielded by IAA-Producing Serratia sp. CK67 in Modified Winogradsky's Culture Medium.

Solutions containing $2.5 \mu \mathrm{M}$ TRP and $5 \mu \mathrm{M}$ of ILA, TOL, and IAA were used as standard solution, of which $5 \mu \mathrm{l}$ was subjected to HPLC. Metabolites of standing-cultured CK67 for 3 weeks redissolved in $2.0 \mathrm{ml} \mathrm{MeOH}$, of which $10 \mu \mathrm{l}$ solution was subjected to HPLC analysis. The scale of the vertical axis shows the concentration of IAA in the cultured medium $(\mu \mathrm{g} / \mathrm{ml})$ as the common indolic compound.

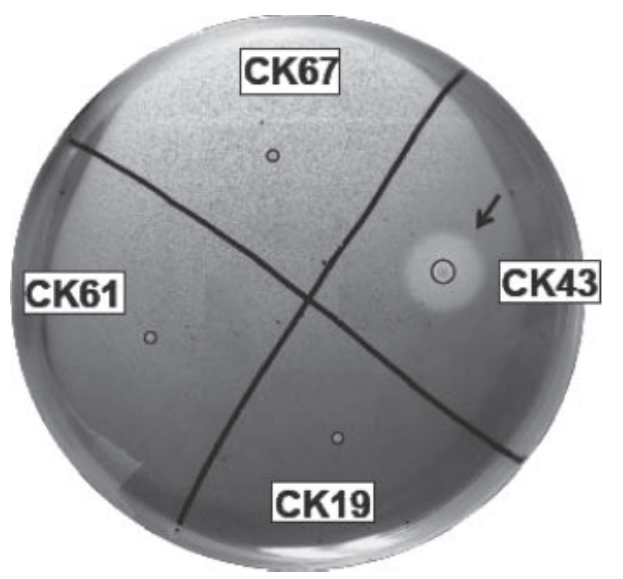

Fig. 5. Positive Response of Burkholderia sp. CK43 to CAS-Plate Assay.

An agar plate $(\phi 9 \mathrm{~cm})$ containing the CAS-Fe complex showed a clear blue color, and as a typical positive response on the CAS-plate assay, CK43 with a yellowish halo-zone around the colony (arrow) is shown. According to the evaluation shown in the footnote to Table 3, Burkholderia sp. CK43 is (++). The other CK61 and CK67 were negative $(-)$, while CK19 was weak positive $( \pm)$. The circle in full line on the plate is to emphasize the edges of the bacterial colonies. The positive responses of CK43 and three more isolates (Pseudomonas sp. CK2, Burkholderia sp. CK28 and Citrobacter sp. CK42) were visible within $4 \mathrm{~d}$ of inoculation.

poor in fume-rich, woody peat soil, ${ }^{12)}$ the Fe-solubilizing activities of the rhizobacteria from Fe-chelates are important in the peatland ecosystem. Among 29 of bacterial isolates tested by CAS assay for iron-solubilizing activity (Table 3), four isolates, Pseudomonas sp. CK2, Citrobacter sp. CK42, and two Burkholderia sp. (CK28 and CK43), formed clear, large yellowish halozones (over $5 \mathrm{~mm}$ in diameter). The largest halo-zone was observed in CK43 as $12 \mathrm{~mm}$ diameter around a $3.8-\mathrm{mm}$ bacterial colony, after $10 \mathrm{~d}$ of incubation at $25^{\circ} \mathrm{C}$ (Fig. 5). ${ }^{38)}$ All these active Fe-chelating bacteria were of the pink type in Salkowski's reagent test. Although Payne has reported that most bacterial ironchelaters are hydroxamide derivatives, ${ }^{24)}$ the Fe-chelating agents produced by these CAS assay-positive bacteria should be characterized. 
Considering all these factors, saplings of dipterocarp trees that are highly adapted to acidic peat soil are likely to be potent sources of functional rhizobacteria, and their responses to Salkowski's reagent, particularly those of the pink type, are closely linked with abilities for specific IAA production, Fe-solubilization, and indole degradation. Among bacteria that showed a colorless response on Salkowski's reagent test, some are probably oligotrophic and have no capability to degrade TRP, while the others have relatively high activities to cleave the indole ring of TRP to yield CA via anthranilic acid. ${ }^{25}$ In fact, some pink type rhizobacteria (CK2, CK13, CK26, and CK43) yielded CA in 2-d shaking culture in TRP-containing medium.

Thus, Salkowski's reagent test, showing alternative coloration due to IAA or reduced product at the $\alpha$ carbon of the TRP skeleton, appears to be quick and useful colorimetric assay for primary screening of functional rhizobacteria, although more types of rhizobacteria not only from tropical peatland but also other terrestrial ecosystems should be investigated. It is also necessary to judge and classify TRP-convertible bacteria into pink and red types, using a more reliable colorimetric index.

\section{Acknowledgments}

This research was supported by a Grant-in-aid for Scientific Research A (no. 20248033 to YH) from JSPS.

\section{References}

1) Sitepu IR, Aryanto, Ogita N, Osaki M, Santoso E, Tahara S, and Hashidoko Y, Tropics, 16, 245-252 (2007).

2) Ahmad F, Ahmad I, and Khan MS, Microbiol. Res., 163, 173181 (2008).

3) Sitepu IR, Hashidoko Y, Aryanto, Turjaman M, Tahara S, Miftahuliyah SS, and Santoso E, J. For. Res., Indonesia, 5, 2135 (2008).

4) Asghar HN, Zahir ZA, Arshad M, and Khaliq A, Biol. Fertil. Soil., 35, 231-237 (2002).

5) Spaepen S, Vanderleyden J, and Remans R, FEMS Microbiol. Rev., 31, 425-448 (2007).

6) Malhotra M and Srivastava S, Eur. J. Soil Biol., 45, 73-80 (2009).

7) Patten CL and Glick BR, Appl. Environ. Microbiol., 68, 37953801 (2002).

8) Fett WF, Osman SF, and Dunn MF, Appl. Environ. Microbiol., 53, 1839-1845 (1987).

9) Kamnev AA, Shchelochkov AG, Perfiliev YD, Tarantilis PA, and Polissiou MG, J. Mol. Struct., 563-564, 565-572 (2001).
10) Perley JE and Stowe BB, Plant Physiol., 41, 234-257 (1966).

11) Koga J, Adachi T, and Hidaka H, Agric. Biol. Chem., 55, 701706 (1991).

12) Ryu RJ and Patten CL, J. Bacteriol., 190, 7200-7208 (2008).

13) Andriesse JP, "Nature and Management of Tropical Peat Soils" Vol. 59, FAO Soils Bulletin, Food and Agriculture Org., p. 112 (1988).

14) Yonebayashi K, Okazaki M, Pechayapisit J, Vijarnsorn P, Zahari AB, and Kyuma K, Soil Sci. Plant Nutr., 40, 425-434 (1994).

15) Kasim S, Ahmed OH, Ab. Majid NM, and Yusop MK, Am. J. Appl. Sci., 5, 1812-1815 (2008).

16) Hashidoko $Y$, Tada M, Osaki M, and Tahara S, Biosci. Biotechnol. Biochem., 66, 2259-2263 (2002).

17) Hara S, Hashidoko Y, Desyatkin R, Hatano R, and Tahara S, Appl. Environ. Microbiol., 75, 2811-2819 (2009).

18) Glickmann E and Dessaux Y, Appl. Environ. Microbiol., 61, 793-796 (1995).

19) Chung K-R, Shilts T, Ertürk Ü, Timmer LW, and Ueng PP, FEBS Microbiol. Lett., 226, 23-30 (2003).

20) Syah YM, Amina NS, Hakim EH, Aimi N, Kitajima M, Takayama H, and Achmad SA, Nat. Prod. Res., 63, 913-917 (2003).

21) Noviany S and Hadi, Mod. Appl. Sci., 3, 45-51 (2009).

22) King FE, King TJ, and Manning LC, J. Chem. Soc., 563-566 (1957).

23) Hiura T, Hashidoko Y, Kobayashi Y, and Tahara S, Anim. Feed Sci. Technol., 155, 1-8 (2010).

24) Payne SM, Meth. Enzymol., 235, 329-344 (1994).

25) Cozzone AJ, Trends Biochem. Sci., 6, 108-110 (1981).

26) Kaneshiro T, Slodki ME, and Plattner RD, Curr. Microbiol., 18, 57-60 (1989).

27) Stainer RY, Hayashi O, and Tsuchida M, J. Bacteriol., 62, 355366 (1951).

28) Laćan G, Magnus V, Simaga S, Iskric S, and Hall PJ, Plant Physiol., 78, 447-454 (1985).

29) Sprunck S, Jacobsen H-J, and Reinard T, J. Plant Growth Regul., 14, 191-197 (2004).

30) Inagaki S, Morimura S, Gondo K, Tang $Y$, Akutagawa $H$, and Kida K, Biosci. Biotechnol. Biochem., 71, 371-379 (2007).

31) Hashidoko Y, Hasegawa T, Purnomo E, Tada M, Limin SH, Osaki M, and Tahara S, Tropics, 14, 139-147 (2005).

32) Kato-Noguchi H, Mizutani J, and Hasegawa K, J. Chem. Ecol., 20, 315-319 (1994).

33) Kravchenko LV, Azarova TS, Makarova NM, and Tikhonovich IA, Microbiology, 73, 195-198 (2004).

34) Kamilova F, Kravchenko LV, Shaposhnikov AI, Azarova T, Makarova N, and Lugtenberg B, Mol. Plant Microbe Interact., 19, 250-256 (2006).

35) Huang H and Villanueva VR, Trees, 7, 189-193 (1993).

36) Ikeda M and Katsumata R, Appl. Environ. Microbiol., 58, 781785 (1992).

37) Merino E, Jensen RA, and Yanofsky C, Curr. Opin. Microbiol., 11, 78-86 (2008).

38) Schwyn B and Neilands JB, Anal. Biochem., 160, 47-56 (1987). 